\title{
General hurricane track and intensity model
}

\author{
B.M. Nguyen \& P.H.A.J.M. Van Gelder \\ Delft University of Technology, Delft, the Netherlands
}

\begin{abstract}
This paper presents a new modeling technique to simulate the entire track of hurricane, starting with their initial points and ending with their landfall locations or final dissipations over the sea. The theoretical framework was first described in the literature by Vickery et al. (2000) and is extended in this study by introducing a new formula and several substantial adjustments. The results show acceptable accuracy, even if the input data are for a short period. For the Vietnam case, the research successfully generates a large database of synthetic storm tracks on the basis of a limited historical track record and sea surface temperature. The model is evaluated through the comparisons between the key storm statistics derived from the observed and simulated data over the entire research area (i.e. the South China Sea). Finally, application of this method to risk assessments is proposed.
\end{abstract}

\section{INTRODUCTION}

\subsection{Natural hazards}

Natural hazards (e.g. earthquake, volcanic eruption, cyclonic storms or drought) are among the greatest threats to mankind. In the areas where vulnerable groups of people are exposed, these extreme natural events result in natural disasters (Blaikie et al. 2003). Every year up to 340 million people are under the influence of natural disasters that leads to the remarkable human, environmental or financial losses (Frerks 2004). Between 1995 and 2004, disasters affected an estimated 2.5 billion people, killed about 890,000 people, and total financial loss was $\$ 570$ billion, according to United Nation International Strategy for Disaster Reduction (UNISDR 2008).

Vietnam is located in the East Asian monsoon sub-system. The country is affected by various types of natural hazards, mostly climatic and atmospheric (e.g. typhoon, drought) and geological (e.g. landslide). Because more than $70 \%$ of the population is exposed to these hazards (Oanh et al. 2011), the consequent disasters have brought about great loss of human life, environmental degradation and damage to infrastructure, private possession, agricultural and industrial land. From 1990-2009, the annual number of death and evaluative total economic toll due to natural hazards was 457 and 1861.5 million US\$ Purchasing Power Parity (PPP), respectively. This financial loss was equivalent to $1.31 \%$ Gross Domestic Product (GDP) (Harmeling 2010).

\subsection{Hurricanes}

Hurricane and typhoon are different names for the same phenomenon, which is a cyclonic storm system initiates over the seas. Among natural hazards, hurricane is the main extreme weather event that causes massive damages to affected areas along its track (Ariffin \& Moten 2009). The resulting disasters have enormous human, economic and social consequences; affect numerous sectors and bring about billions US dollars of property damages. In addition, storm surge and large waves generated by typhoons can erode the beach and dune system and reshape the coastal landscape (Brettschneider 2006). According to Tompkins (2002), three of the top five costliest and deadliest weather related disasters for 19702001 were hurricanes.

Located in one of the five storm-prone areas of the Asia Pacific region, with a long coastline of approximately $3440 \mathrm{~km}$ (Oanh et al. 2011) and densely populated river deltas and coastal areas, Vietnam is among the top five countries most affected by weather related loss events, particularly by typhoons (Dasgupta et al. 2009). The country has annually affected by flooding, and frequently by hurricanes. On average, there are six to eight typhoons each year, according to United Nations Development Program (UNDP 2007). Figure 1 shows the geographic range of the South China Sea - the ocean region that has directly effects on Vietnam. 


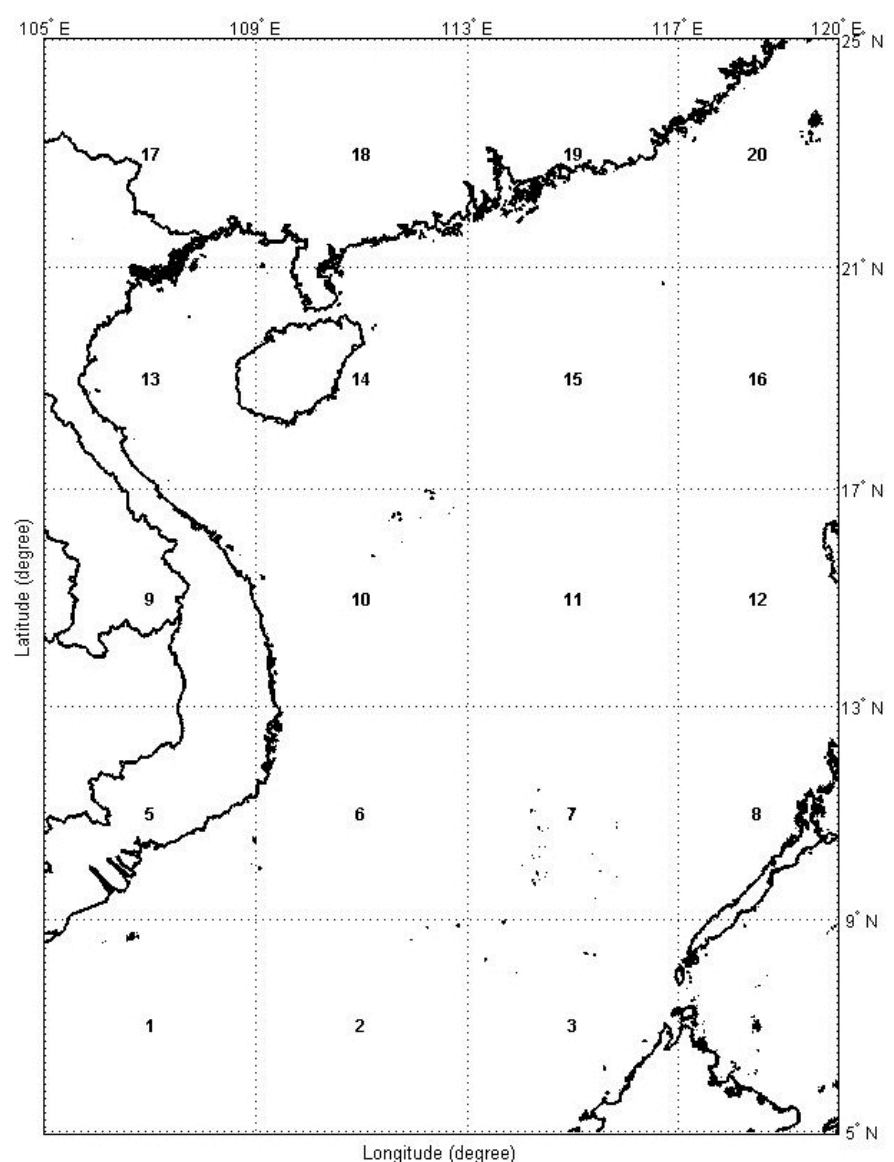

Figure 1. The South China Sea.

\subsection{Hurricane risk reduction}

An easy to understand definition of hurricane risk is the estimated degree of threat facing a vulnerable group of people through exposure to hurricanes (World Vision 2009). The more susceptible the community (in various means, such as physically, economically, environmentally, or socially) the more expensive and deadly the typhoons. While hurricanes are unavoidable, their risk can be considerably lessened. It can be done either by decreasing the vulnerabilities and/or by increasing the capacities of the affected population to withstand typhoons, that is, their resilience.

Numerous approaches have been executed to lessen hurricane risk, including both structural and non-structural methods. Structural solution is basically a sufficient number of proper-design coastal defense structures (i.e. hard engineering methods such as sea walls, floodgates, revetments, and offshore breakwaters), which can cope with the impacts of severe typhoon winds and storm surges at a certain level. Non-structural techniques are based on the successful hurricane early warning programs and predictive models of morphological impacts induced by extreme typhoons. They include soft engineering approaches (e.g. beach nourishment, sand dune stabilization, beach drainage), advanced building codes and their enforcement, master planning of coastal zone, increasing the effective of preparative solu- tions (e.g. evacuation strategies), and giving more helpful warning time for hurricanes.

Acknowledging the country's vulnerability, over recent years Vietnam has made great efforts to relieve poorness and verge upon achieving the Millennium Development Goals. Because the Vietnamese government notices the close relationship between vulnerability to natural disasters and poverty, a considerable amount of money have been spent to support various risk reduction campaigns. For example, from 2009-2015, \$143 million would be paid out to address climate change only (World Vision 2009).

\section{LITERATURE REVIEW}

\subsection{Hurricane risk assessment}

When typhoons hit the coast, they bring along many devastating impacts. As hurricanes near land, their intense winds, which can reach up to $200 \mathrm{mph}$ (i.e. $322 \mathrm{~km} / \mathrm{h}$ ) (Hearn 2004), produce storm surges - the rising walls of ocean water sweep through the entire affected coastal regions. This wind-induced surge that can be $6 \mathrm{~m}$ high at its peak and 80 to $160 \mathrm{~km}$ wide, according to United States Federal Emergency Management Agency (FEMA 2001), is the most significant effect from a typhoon. Furthermore, it has been estimated to account for most of human losses, i.e. nearly $90 \%$ of all hurricane-related injuries and fatalities throughout history (Shultz et al. 2005). After typhoons come ashore, they generate heavy precipitation that cause tremendous freshwater flooding in rivers and urban areas. These floods afterward can also trigger landslide along riverbank as well as mountainous and hilly regions. In several cases (e.g. Hurricane Floyd or Hurricane Mitch), loss of lives and destruction of properties mainly originate from inland flooding.

However, although typhoon-induced rainfall and its implications cannot be ignored, almost all existing hurricane risk assessment techniques associated with only typhoon winds (Emanuel et al. 2006). The underlying reason is currently, knowledge of hurricane rains have not yet reached to a certain level that can be a reliable basic of trustful rainfall predictions. In addition, historical records of typhoon winds are much more complete and therefore, extensive enough to make effective evaluations of hurricane risks.

\subsection{Historical typhoon records}

One meaningful approach to assess typhoon risks, which can occur at a specific location, is to analyze what already happened in the past. Thus, all current hurricane estimation methods are based on historical records of typhoon tracks and intensities. The typical representations of these compilations are the alleged "best track" records, which are stored, maintained 
and annually updated by several meteorological agencies, such as the global dataset provided by the United States Navy's Joint Typhoon Warning Center (JTWC) or National Oceanic and Atmospheric Administration's (NOAA's) Tropical Prediction Center (TPC) and the local one from the Regional Specialized Meteorological Center (RSMC) operated by the Japan Meteorological Agency (JMA) (Emanuel et al. 2006). For each reported hurricane, the catalogs generally give some typhoon-related information such as the center position in geodetic coordinate (i.e. latitude and longitude) together with intensity estimation (i.e. maximum sustained wind speed and/or central pressure) at six-hour intervals along hurricane track since its initiation (Darling 1991, Jarvinen et al. 1984). These data sets provide a crucial reference in understanding typhoons occurred previously, from which proper risk assessment techniques can be initiated and evolved.

\subsection{Data scarcity issue}

Typhoon estimations has developed in great demand for reliable risk-based technical evaluation, which is rising along with the increasing in exposure to stronger, more often, rapidly changing and less predictable hurricanes (Vickery et al. 2009). Because existing approaches directly base on available observed data (Emanuel et al. 2006), the most crucial limitation relates to the small sample size because hurricanes are both relatively infrequent and small in terms of the length of coastlines affected by these typhoons each year. When coupled with the often low-quality data sets, these techniques can lead to very unreliable evaluations of hurricane frequencies and intensities along the coast. Therefore, it is difficult to derive accurate key parameter of the strongest typhoons, on which risk analysis and design of coastal defense structures must be relied (Hallegatte 2007). In some particular places (e.g. New England in the United States), although the locations have been hardly stricken by hurricane, the possible consequences of a land falling typhoons are massive due to current densely populated urban areas, great economic values of properties and high insurance levels. However, due to the shortness of reported hurricane compilation, there is no trustful estimate available at the moment.

In Vietnam, hurricane risk study is especially problematic and preliminary research usually faces numerous difficulties. Generally, there is not any complete database on natural hazards, particularly typhoon, nor a systematic method, tool or software to store, maintain and analyze this record (Oanh et al. 2011). Observations have been measured, stored and assessed locally, at provincial level. This collection and management methodology leads to an inconsistent and normally non-electrically national compilation. Moreover, the potential problem with sole reliance on observed hurricanes becomes more serious because of budget constraints, lack of suitable techniques, use of observing equipment that produces little reliable data, and also, historically, the aftermath of war in the country from 1945 to 1975. While data sets of typhoon tracks and intensities for more than 150 years are available for many other regions (e.g. North and South Atlantic, East Pacific, North Indian), hurricanes in the South China Sea have only been monitored since the end of World War II by RMSC - a foreign organization. Because local nearshore measurements are not presented, typhoon risk assessment in Vietnam suffers a lot from the data scarcity issue.

Therefore, there is a rising demand for advanced techniques that can compensate for the lack of reliable hurricane observations, in order to step up classical hurricane estimation methods and upgrade current risk assessment and management.

\subsection{Wind loss estimating techniques}

In appreciation of the above, it is important to review existing methods and the manner in which these approaches are being applied to specific circumstances. Currently, numerical modeling is the most accepted technique for estimating hurricane wind speed, which is widely used to design coastal structures and to assess the risks associated with typhoon winds. According to Resio et al. (2007), at least five techniques have been utilized to investigate hurricane parameters in past studies. These methodologies include the formulation of design storm events, the Peaks Over Threshold (POT) approach, Empirical Simulation Technique (EST), Joint Probability Method (JPM), and empirical track model. Among them, the design storm method inhibits the real variation in typhoon parameters. This approach utilizes only one factor, typically intensity, for the modeling processes of hurricane's initiation and evolution. On the other hand, other conventional methods (e.g. POT, EST, and JPM) suffer greatly from a paucity of historical compilations (Resio et al. 2007).

The empirical track model, which was introduced by Vickery et al. (2000), is one of the most recent techniques. The authors successfully generated typhoons over a very long period (i.e. 20,000 years) using available track observations and local climatological variables (Brettschneider 2006). According to Ravela \& Emanuel (2010), the most important improvement of this method over conventional techniques is that it removes the need to specify a parametric form for the distributions of key hurricane parameters in the critical range of values. Therefore, this approach provides an excellent source for validating the statistical characteristics of the typhoon (Resio et al. 2007). 


\section{METHODOLOGY}

\subsection{Theoretical framework}

Taking into account the above-mentioned situation, the main objective of this research is to develop a suitable method for the simulation of hurricanes on the basis of the available historical record.

In this study, the empirical track model is chosen as the theoretical framework because of its potential advantages over other techniques. The track of a typhoon is modeled, starting with its initial point and ending with its landfall location or point of final dissipation over the sea. Using this approach, a user can compute 6-h changes in hurricane heading, translation speed, and wind speed along this track as linear functions of previous values of those parameters as well as typhoon center location and Sea Surface Temperature (SST). Thus, a large database of synthetic tracks is generated that is based on a limited observed track compilation and a local climatological variable (i.e. SST). This method is validated through comparisons between the hurricane statistics derived from the historical data and the simulated ones over the whole South China Sea region.

\subsection{Data sources}

The most important input for an empirical track model is the observed track record. For the Vietnamese case study, the RSMC Best Track Data (JMA - RSMC Tokyo - Typhoon Center 2012) is used. This compilation is one of the most complete and recent databases, which includes the historical track for every single hurricane that occurred within the South China Sea area from 1951 to 2011.

Another data collection used is the NOAA NCDC ERSST version $3 b$ (IRI/LDEO Climate Data Library 2012), which contains the global extended reconstructed monthly SST values. Finally, the digital coastline map of the South China Sea is provided by the NOAA National Geophysical Data Center (NGDC) Marine Geology \& Geophysics Division and collocated by World Data Center for Marine Geology \& Geophysics, Boulder (Signell 2012).

Because all the required data can be searched and extracted from global databases, this approach can be applied to all other locations.

\subsection{Empirical track modeling}

The number of typhoons, which have to be simulated each year, is sampled from a negative binomial distribution with a mean value of 10.05 (hurricanes/year) and a standard deviation of 3.61 (hurricanes/year). This distribution is estimated using the observed annual number of hurricanes in the research area (i.e. the South China Sea). The starting position of typhoon center and all relevant parameters including the month of occurrence, heading, translation speed, and wind speed are sampled from a set of hurricane initiations. This series is derived from the surveyed track database by selecting the first location of each historical typhoon, which was inside the research area. The significance of this sampling method is to retain all the climatology data combined with any seasonal preferences for the point of hurricane initiation (Vickery et al. 2000).

Given these original conditions, the new position, translation speed, heading, and wind speed are estimated based on the changes in these parameters over the current 6-h period using Equations 1, 2, and 3. They are written in a general form, which can be used for any time period (i.e. between the time steps $i$ and $i+1)$ :

$$
\Delta \operatorname{lnc}_{\mathrm{i}}=\operatorname{lnc}_{\mathrm{i}+1}-\operatorname{lnc}_{\mathrm{i}}=\mathrm{a}_{1}+\mathrm{a}_{2} \times \Psi_{\mathrm{i}}+\mathrm{a}_{3} \times \lambda_{\mathrm{i}}+\mathrm{a}_{4} \times \operatorname{lnc}_{\mathrm{i}}
$$$$
+\mathrm{a}_{5} \times \theta_{\mathrm{i}}+\mathrm{a}_{6} \times \theta_{\mathrm{i}-1}+\varepsilon_{\mathrm{i} 1}
$$

$$
\Delta \theta_{\mathrm{i}}=\theta_{\mathrm{i}+1}-\theta_{\mathrm{i}}=\mathrm{b}_{1}+\mathrm{b}_{2} \times \Psi_{\mathrm{i}}+\mathrm{b}_{3} \times \lambda_{\mathrm{i}}+\mathrm{b}_{4} \times \mathrm{c}_{\mathrm{i}}+\mathrm{b}_{5} \times
$$

$\theta_{\mathrm{i}}+\mathrm{b}_{6} \times \theta_{\mathrm{i}-1}+\varepsilon_{\mathrm{i} 2}$

$$
\begin{aligned}
& \Delta \mathrm{u}_{\mathrm{i}}=\mathrm{u}_{\mathrm{i}+1}-\mathrm{u}_{\mathrm{i}}=\mathrm{c}_{1}+\mathrm{c}_{2} \times \mathrm{T}_{\mathrm{i}}+\mathrm{c}_{3} \times \mathrm{T}_{\mathrm{i}-1}+\mathrm{c}_{4} \times \mathrm{u}_{\mathrm{i}}+\mathrm{c}_{5} \\
& \times \mathrm{u}_{\mathrm{i}-1}+\varepsilon_{\mathrm{i} 3}
\end{aligned}
$$

where $\Psi$ and $\lambda=$ latitude and longitude of typhoon center, respectively; $c=$ translation speed; $\theta=$ heading; $\mathrm{T}=$ sea surface temperature; $\mathrm{u}=$ maximum sustained wind speed; $\varepsilon=$ random error.

The symbol $\Delta$ situated before each parameter denotes the change of this quantity over the current period; the subscripts $i$ and $i+1$ specified for each parameter express the value at the corresponding time step; and $\mathrm{a}_{1}, \mathrm{a}_{2}$, etc. is a set of constants for each rectangular grid cell within the research area. When the hurricane travels from one grid cell to another, these values are changed accordingly. The constants are computed using a multiple linear regression solution. Because this process is repeated until the synthetic typhoon makes landfall or final dissipation over the sea, a full track is created, along with all main parameters, at each time step.

Equation 3 is a new mathematical expression that is first introduced by this research. Unlike the conventional empirical track approach by Vickery et al. (2000) that gives an indirect estimation using a hurricane wind field model, this method can be used to directly compute the most important hurricane parameter, that is, wind speed. Furthermore, various model alternatives are also considered to determine the options, which are best suited to the specific conditions of the South China Sea. For instance, three different multiple linear regression solutions are utilized: the ordinary least squares, the robust and stepwise algorithms. However, none of the above techniques can generally be employed for datasets with less than 6 data points, because they lead to very unreliable results. Although the small grid size may result in a better correlation between parameters, it also increases the number of lacking- 
data grid cells (i.e. grid cells containing fewer than 6 data points). Therefore, various grid sizes (i.e. $2.5^{\circ} \times$ $2.5^{\circ}, 4^{\circ} \times 4^{\circ}$, and $5^{\circ} \times 5^{\circ}$ ) are examined.

\section{MODEL EVALUATION}

The above methodology is validated through comparisons between historical and modeled statistics, which are obtained from a 10,000-year simulation over the entire South China Sea. Because the evaluation is given within the whole region, all typhoons are taken into account, even if they end at the ocean or only pass through the research area. This is an improvement over the research by Vickery et al. (2000). In that pioneering study, only hurricanes that enter the sub-regions around certain Points Of Interest (POIs) are taken into account. Because those POIs are normally situated at the coastline, typhoons that do not make landfall were ignored, although they are still very important for various sectors.

Synthetic hurricanes are initiated using available historical track records and propagated over water using Equations 1, 2, and 3 to estimate their locations and parameters. The ordinary least square technique and $4^{\circ} \times 4^{\circ}$ grid size are chosen as the optimal multiple linear regression solution and the optimal spatial size, respectively, due to their better performance in terms of model results (i.e. higher correlation coefficients) than other options.

In terms of qualitative evaluation, the mean and standard deviation of translation speed, heading, and wind speed of both observed and simulated typhoons are computed and plotted in the same figures as shown in Figure 2. As one can clearly see in the figures, the modeled data are very close to the historical ones.

Quantitative assessment is also carried out by plotting the Probability Density Function (PDF) of both observed and simulated main statistics and computing the correlation coefficients between those values. The correlation coefficients are always between -1 and 1 . When these quantities are close to 1 , the historical and modeled data are highly (positively) correlated. Furthermore, a comparison between these PDFs can also be made with a chisquare statistic. When it is smaller than the critical value, the observed and simulated key parameters are considered to have the same distribution shape. With degree of freedom of 1 and significance level of 0.05 ; the critical chi-square value is 3.84 (Boslaugh \& Watters 2008). Figure 3 gives these comparisons for translation speed, heading, and wind speed. In this figure, all the correlation coefficients are close to 1 (i.e. 0.9937, 0.8971, and 0.92803 for the translation speed, heading, and wind speed statistics, respectively). The chi-square statistics are much smaller than 3.84 (i.e. 0.049381, 0.28898 , and 0.14483 for the translation speed, heading, and wind speed, respectively). Therefore, one can conclude that the main statistics derived from simulation can describe observed hurricanes remarkably well.

\section{APPLICATION TO RISK ASSESSMENT}

Among various typhoon effects, extremely powerful winds and damaging storm surges are two major destructive causes of most human and financial losses. Thus, hurricane risk can be calculated as follow:

$R^{\text {hurricane }}=R^{\text {wind }}+R^{\text {surge }}$

where $\mathrm{R}=$ the risk associated with the loss due to a threat, which is specified in the superscripts of each term.

Typhoons are divided into several groups according to their intensities (i.e. wind speed) by using a ranking system. Consequently, one can compute those component risks (i.e. wind and surge) as the sum of the risks for each different group. For instance, when using Saffir-Simpson scale, which classifies hurricanes into five categories, the below formulae are applicable:

$R^{\text {wind }}=\sum_{i=1}^{5} P_{i} C_{i}^{\text {wind }}$
$R^{\text {surge }}=\sum_{i=1}^{5} P_{i} C_{i}^{\text {surge }}$

where $\mathrm{P}_{\mathrm{i}}=$ the probability that a category $\mathrm{i}$ typhoon will occur in any given year; and $C_{i}=$ the cost of the loss if such hurricane occurs due to the impact mentioned in the superscript.

At any location, the risk assessment can be done using the simulation results and some other tools. First, the large set of modeled typhoons is spitted into five subsets corresponding to different hurricane categories using Saffir-Simpson scale. The rate of occurrence (i.e. $\mathrm{P}_{\mathrm{i}}$ ) is determined directly by counting the number of synthetic tracks in each subset that pass current location. Wind damage (i.e. $\mathrm{C}_{\mathrm{i}}^{\text {wind }}$ ) is the losses due to high wind. It is the sum of the values of effected properties (if totally destroyed) or portion of those values (in case of partially damaged properties). When couple with a storm surge model, one can calculate the wind-induced surge based on typhoon statistics derived from empirical track model. Afterwards, that resulting value is put into a coastal inundation model to estimate losses caused by storm surge (i.e. $\mathrm{C}_{\mathrm{i}}^{\text {surge }}$ ). 

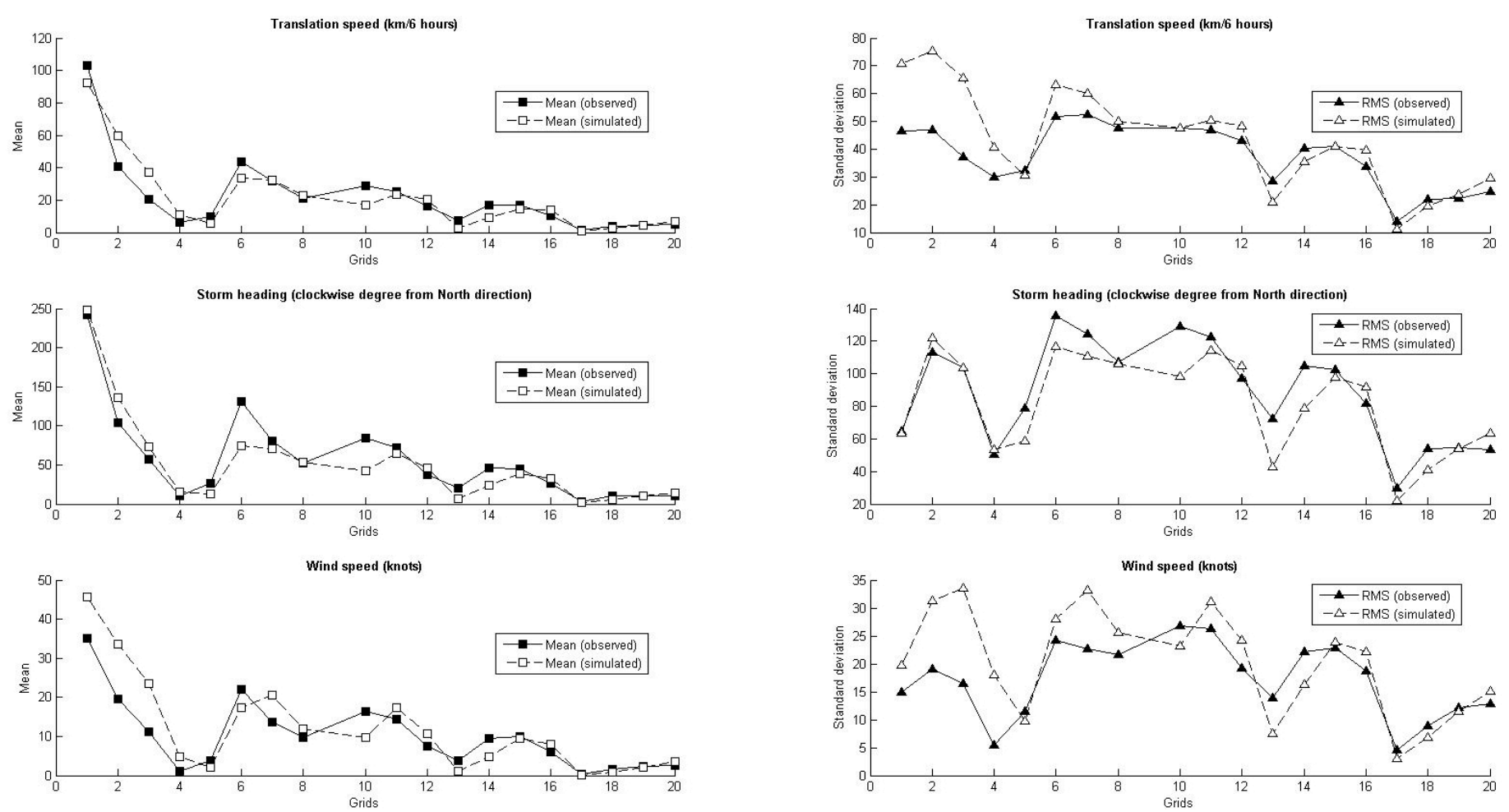

Figure 2. Qualitative evaluation.
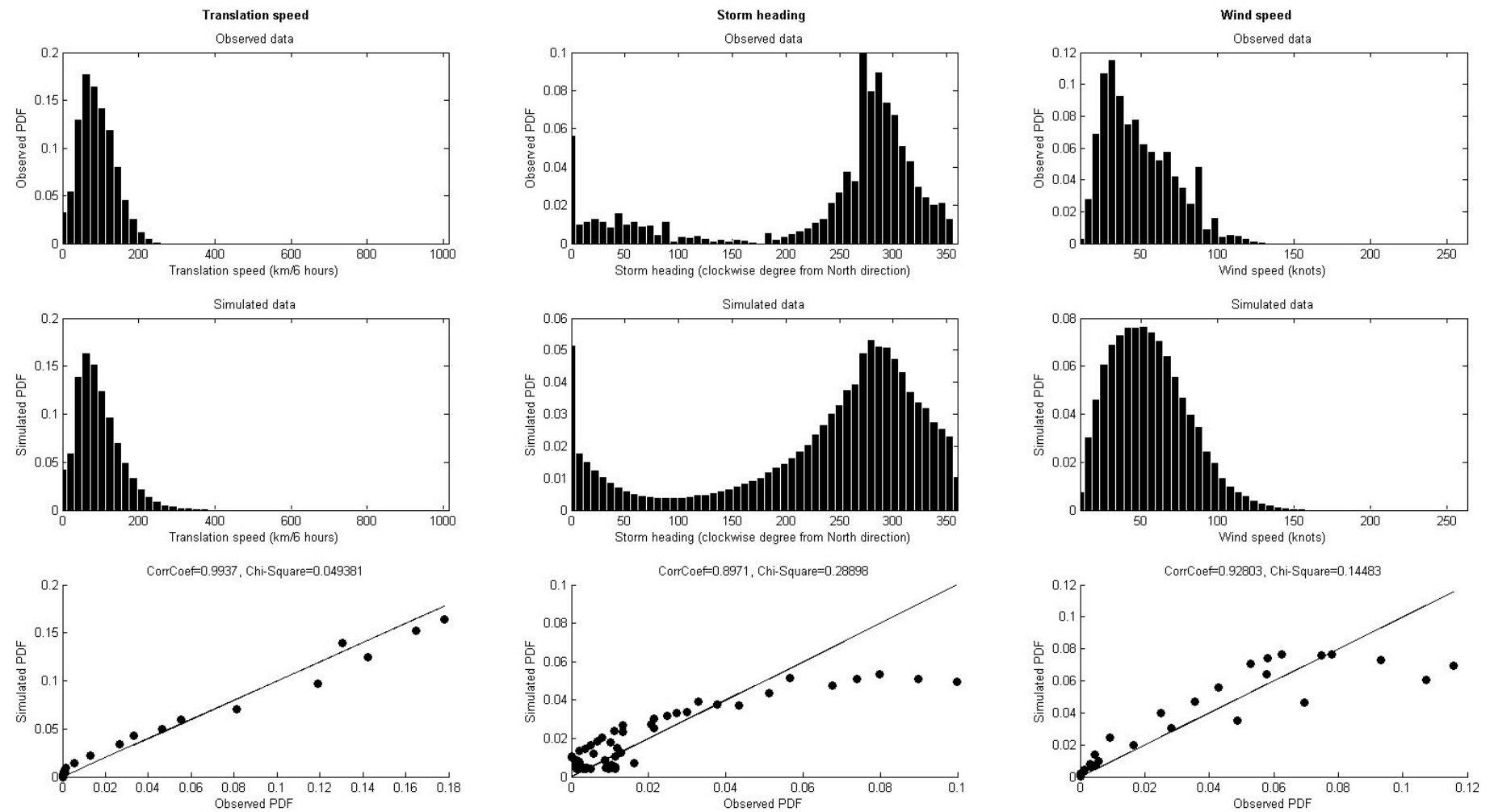

Figure 3. Quantitative comparison. 


\section{CONCLUSIONS}

A new modeling technique to simulate the entire track of a hurricane in the South China Sea region has been presented. Some crucial enhancements are proposed by using the empirical track framework to compensate for conditions in which there are data shortages. The model validation is executed over the entire research area and shows a very close correlation between observed and modeled data. There is persuasive evidence that indicates that this model has many improved features compared to other models. Moreover, all the required data can be searched and extracted from global databases. Thus, the methodology mentioned in this study can be applied to other research at different locations. Finally, application to risk assessment is proposed.

\section{REFERENCES}

Ariffin, M., and Moten, S. 2009. Relationship Between Maximum Sustained Wind Speed and Central Pressure of Tropical Cyclones. Malaysia: Malaysian Meteorological Department.

Blaikie, P., Cannon, T., Davis, I. \& Wisner, B. 2003. At Risk: Natural Hazards, People's Vulnerability and Disasters. United Kingdom: Routledge.

Boslaugh, S. \& Watters, P. A. 2008. Statistics in a nutshell. United States: O'Reilly Media, Inc.

Brettschneider, B. 2006. Estimating Atlantic Basin Tropical Cyclone Landfall Probability for the United States. Theses and Dissertations-Geography. United States: Texas State University-San Marcos.

Darling, R. W. R. 1991. Estimating Probabilities of Hurricane Wind Speeds Using a Large-Scale Empirical Model. Journal of Climate 4(10): 1035-1046.

Dasgupta, S., Laplante, B., Meisner, C., Wheeler, D. \& Yan, J. 2009. The impact of sea level rise on developing countries: a comparative analysis. Climatic Change 93(3): 379-388.

Emanuel, K., Ravela, S., Vivant, E. \& Risi, C. 2006. A Statistical Deterministic Approach to Hurricane Risk Assessment. Bulletin of the American Meteorological Society 87: 299314.

FEMA 2001. Surviving the storm a guide to hurricane preparedness. United States: Federal Emergency Management Agency.

Frerks, G. 2004. Mapping Vulnerability: Disasters, Development and People. United Kingdom: Routledge.

Hallegatte, S. 2007. The Use of Synthetic Hurricane Tracks in Risk Analysis and Climate Change Damage Assessment. Journal of Applied Meteorology and Climatology 46(11): 1956-1966.

Harmeling, S. 2010. Global climate risk index 2011. Germany : Germanwatch.

Hearn, P. D. 2004. Hurricane Camille: Monster Storm of the Gulf Coast. United States: University Press of Mississippi.

IRI/LDEO Climate Data Library 2012. NOAA NCDC ERSST version $3 b$.

$<$ http://iridl.ldeo.columbia.edu/SOURCES/.NOAA/.NCDC/ .ERSST/.version3b/> (Mar. 29, 2012).

Jarvinen, B. R., Neumann, C. J., Davis, M. A. S. \& United States. National Weather Service 1984. A tropical cyclone data tape for the North Atlantic Basin, 1886-1983: contents, limitations, and uses. NOAA technical memorandum NWS NHC 22. United States: U.S. Dept. of Commerce, Na- tional Oceanic and Atmospheric Administration, National Weather Service.

JMA - RSMC Tokyo - Typhoon Center 2012. RSMC Best Track Data. <http://www.jma.go.jp/jma/jma-eng/jmacenter/rsmc-hp-pub-eg/besttrack.html > (Mar. 29, 2012).

Oanh, L. N., Nguyen, T. T. T., Wilderspin, I. \& Coulier, M. 2011. A preliminary analysis of flood and storm disaster data in Viet Nam. Global Assessment Report on Disaster Risk Reduction 2011. Vietnam: United Nations Development Program (UNDP).

Ravela, S. \& Emanuel, K. A. 2010. Statistical-deterministic approach to natural disaster prediction. United States.

Resio, D.T., Borgman, L., Cardone, V.J., Cox, A., Dally, W.R., Dean, R.G., Divoky, D., Hirsh, E., Irish, J.L., Levinson, D., Niederoda, A., Powell, M.D., Ratcliff, J.J., Stutts, V., Suhada, J., Toro, G.R., Vickery, P.J.,D. T., Borgman, L. \& Boc, S. J. 2007. White Paper on Estimating Hurricane Inundation Probabilities. United States: U.S. Army Corps of Engineers.

Shultz, J. M., Russell, J. \& Espinel, Z. 2005. Epidemiology of Tropical Cyclones: The Dynamics of Disaster, Disease, and Development. Epidemiologic Reviews 27(1): 21-35.

Signell, R. 2012. Coastline Extractor. $<$ http://www.ngdc.noaa.gov/mgg/coast/> (Mar. 29, 2012).

Tompkins, H. 2002. Climate change and extreme weather events: Is there a connection?. Cicerone 2002(3).

UNDP (ed.) 2007. Human Development Report 2007/2008: Fighting Climate Change - Human Solidarity in a Divided World. United Nations Development Programme.

UNISDR 2008. Links between disaster risk reduction, development and climate change: A briefing for Sweden's Commission on Climate Change and Development. Sweden: United Nation International Strategy for Disaster Reduction.

Vickery, P. J, Skerlj, P. F. \& Twisdale, L. A. 2000. Simulation of Hurricane Risk in the U.S. Using Empirical Track Model. Journal of Structural Engineering 126(10): 1222-1237.

Vickery, Peter J., Masters, F. J., Powell, M. D. \& Wadhera, D. 2009. Hurricane hazard modeling: The past, present, and future. Journal of Wind Engineering and Industrial Aerodynamics 97(7-8): 392-405.

World Vision 2009. Reduce Risk and Raise Resilience. Climate Change Series. Australia: World Vision International. 